---Supporting Information---

\title{
Catalytic Conversion of Chitosan to Glucosaminic Acid by Tandem Hydrolysis and Oxidation
}

Jinhang Dai ${ }^{a, b}$, Gökalp Gözaydin ${ }^{a}$, Changwei Hu*b, and Ning Yan*a

${ }^{a}$ Department of Chemical and Biomolecular Engineering, National University of Singapore, BLK E5, 4 Engineering Drive 4, 117585, Singapore

${ }^{\mathrm{b}}$ Key Laboratory of Green Chemistry and Technology, Ministry of Education, College of Chemistry, Sichuan University, No. 29 Wangjiang Road, Chengdu, Sichuan 610064, China

*Corresponding author, E-mail: ning.yan@nus.edu.sg; changweihu@ssu.edu.cn

\section{Table of Contents}

Number of pages in the supporting information: 9

Number of figures in the supporting information: 6

Number of tables in the supporting information: 2 
Table S1. pKa value of various acids and $\mathrm{pH}$ value of corresponding chitosan saltwater mixtures.

\begin{tabular}{cccc}
\hline Entry & Acids & $\mathrm{pKa}$ & $\mathrm{pH}^{\mathrm{a}}$ \\
\hline 1 & $\mathrm{CH}_{3} \mathrm{COOH}$ & 4.75 & 4.47 \\
2 & $\mathrm{H}_{3} \mathrm{PO}_{4}$ & 2.12 & 2.56 \\
3 & $\mathrm{HSO}_{4}^{-}$ & 1.92 & - \\
4 & $\mathrm{HNO}_{3}$ & $<1$ & 1.57 \\
5 & $\mathrm{HCl}_{2}$ & $<1$ & 1.81 \\
6 & $\mathrm{H}_{2} \mathrm{SO}_{4}$ & $<1$ & 1.20 \\
\hline
\end{tabular}

a The chitosan salt-water mixtures were prepared by mixing chitosan $(0.18 \mathrm{mmol}, 31$ $\mathrm{mg})$ and liquid acids $(0.18 \mathrm{mmol})$ in $3 \mathrm{~mL}$ water at room temperature. 


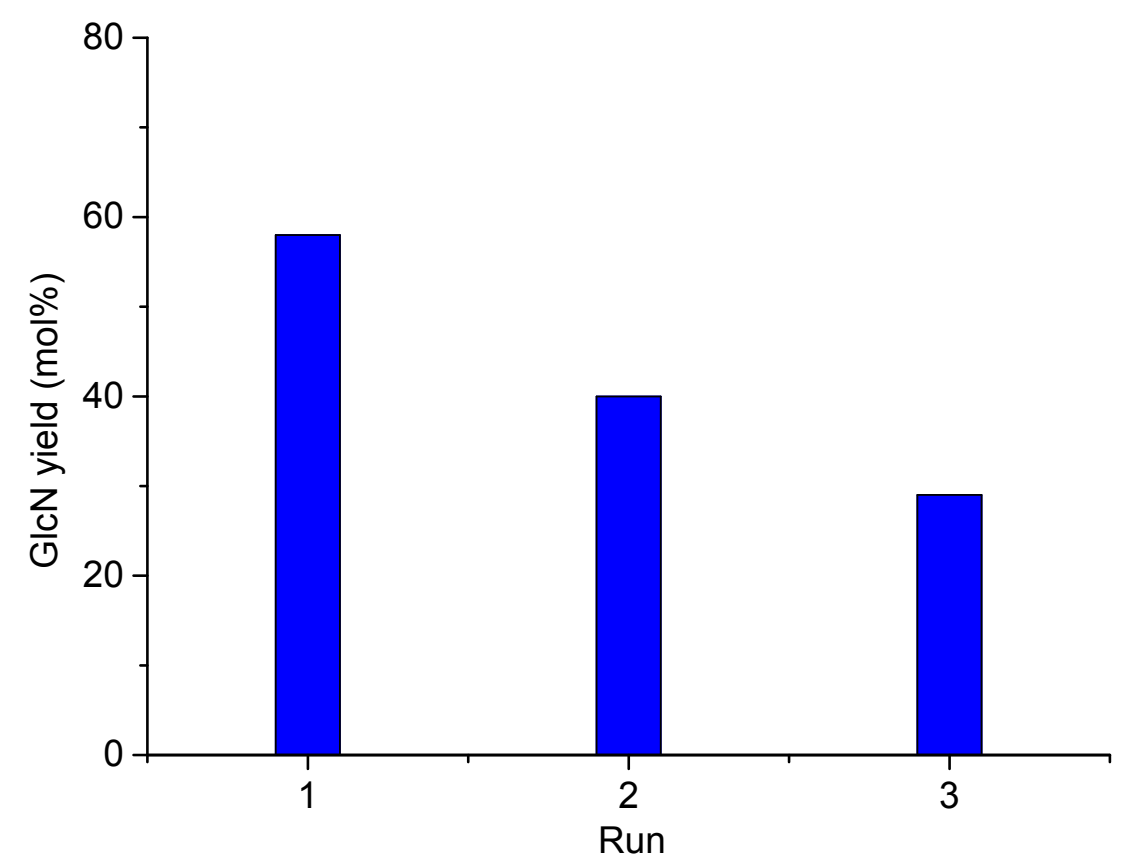

Figure S1. The recyclability of Amberlyst-15.

Reaction conditions: $0.18 \mathrm{mmol}$ chitosan- $\mathrm{H}_{2} \mathrm{SO}_{4}, 30 \mathrm{mg}$ Amberlyst-15, $3 \mathrm{~mL}$ water, $160^{\circ} \mathrm{C}, 2 \mathrm{~h}$.

After hydrolysis reaction, the used Amberlyst-15 was washed with water and dried overnight before next catalytic run. For the second catalytic run, the GlcN yield decreased from $58 \%$ to $40 \%$, indicating the loss of activity. The possible partial decomposition of Amberlyst-15 might be responsible for the decrease of activity. 

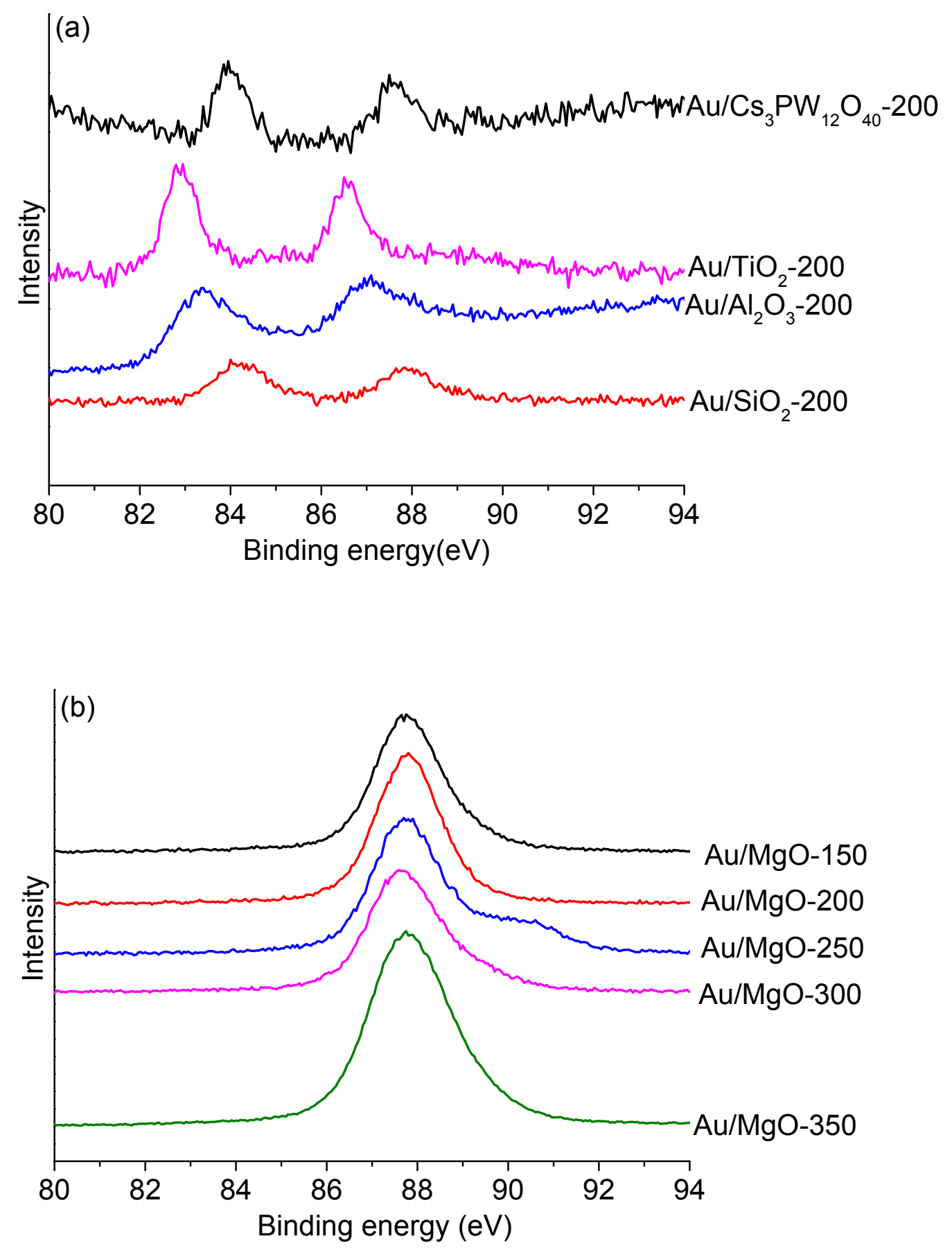

Figure S2. (a) XPS spectra ( $\mathrm{Au} 4 \mathrm{f}$ ) of $\mathrm{Au} / \mathrm{Cs}_{3} \mathrm{PW}_{12} \mathrm{O}_{40}, \mathrm{Au} / \mathrm{TiO}_{2}, \mathrm{Au} / \mathrm{Al}_{2} \mathrm{O}_{3}$, and $\mathrm{Au} / \mathrm{SiO}_{2}$; and (b) XPS spectra ( $\mathrm{Au} 4 \mathrm{f}$ and $\mathrm{Mg}$ 2s) of $\mathrm{Au} / \mathrm{MgO}-150,200,250,300$, and 350. 


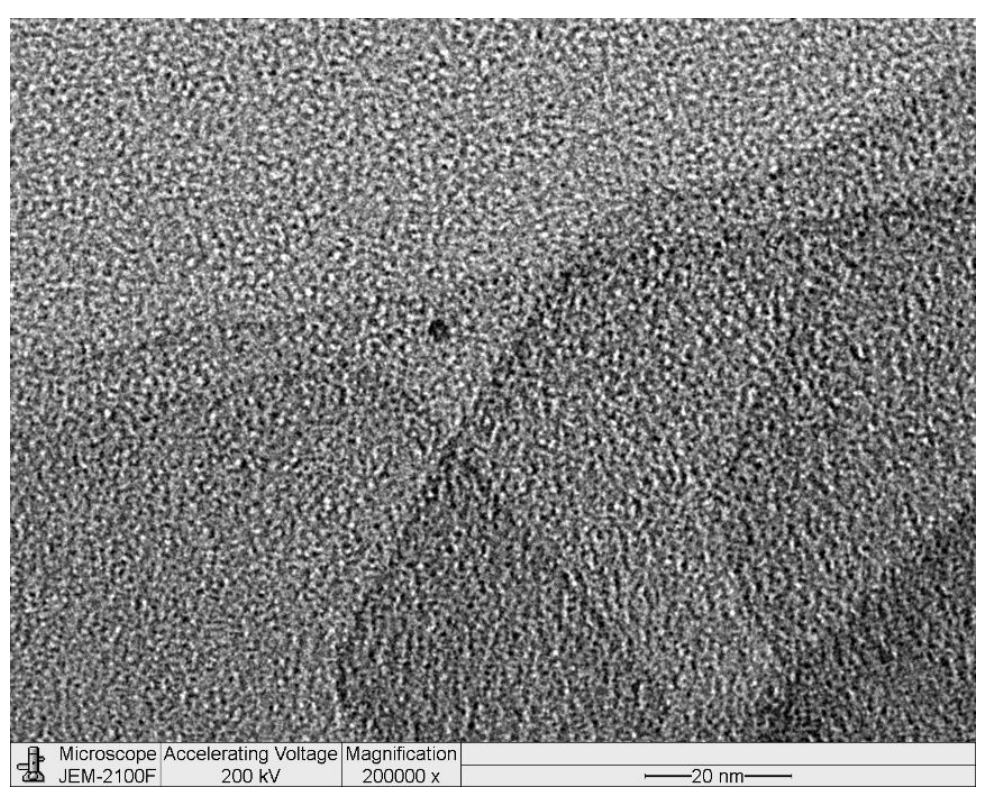

Figure S3. The TEM image of $\mathrm{Au} / \mathrm{MgO}-200$ catalyst. 

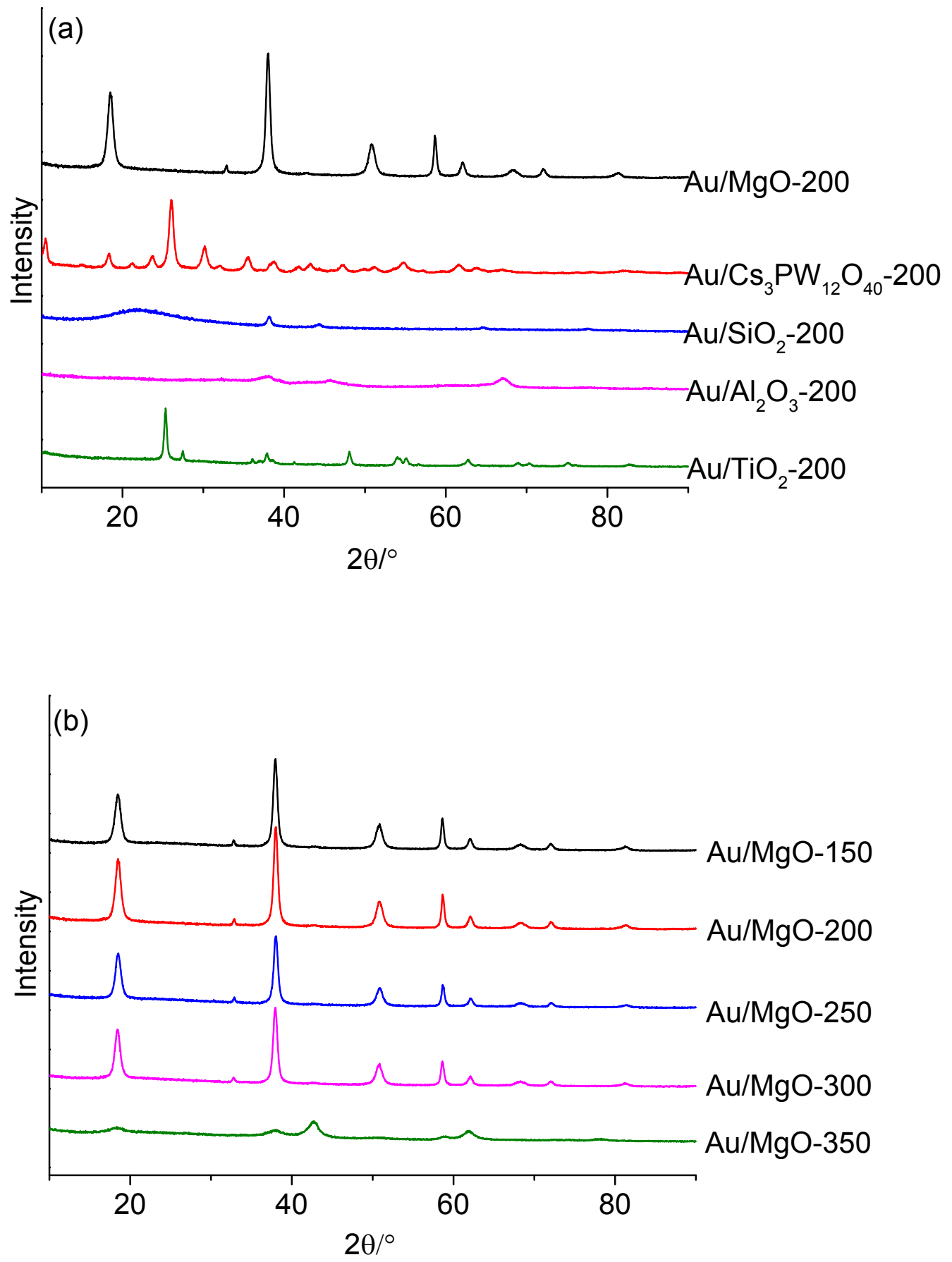

Figure S4. X-ray diffraction patterns of (a) $\mathrm{Au} / \mathrm{MgO}-200, \mathrm{Au} / \mathrm{Cs}_{3} \mathrm{PW}_{12} \mathrm{O}_{40}, \mathrm{Au} / \mathrm{TiO}_{2}$, $\mathrm{Au} / \mathrm{Al}_{2} \mathrm{O}_{3}$, and $\mathrm{Au} / \mathrm{SiO}_{2}$; and (b) $\mathrm{Au} / \mathrm{MgO}-150,200,250,300$, and 350. 


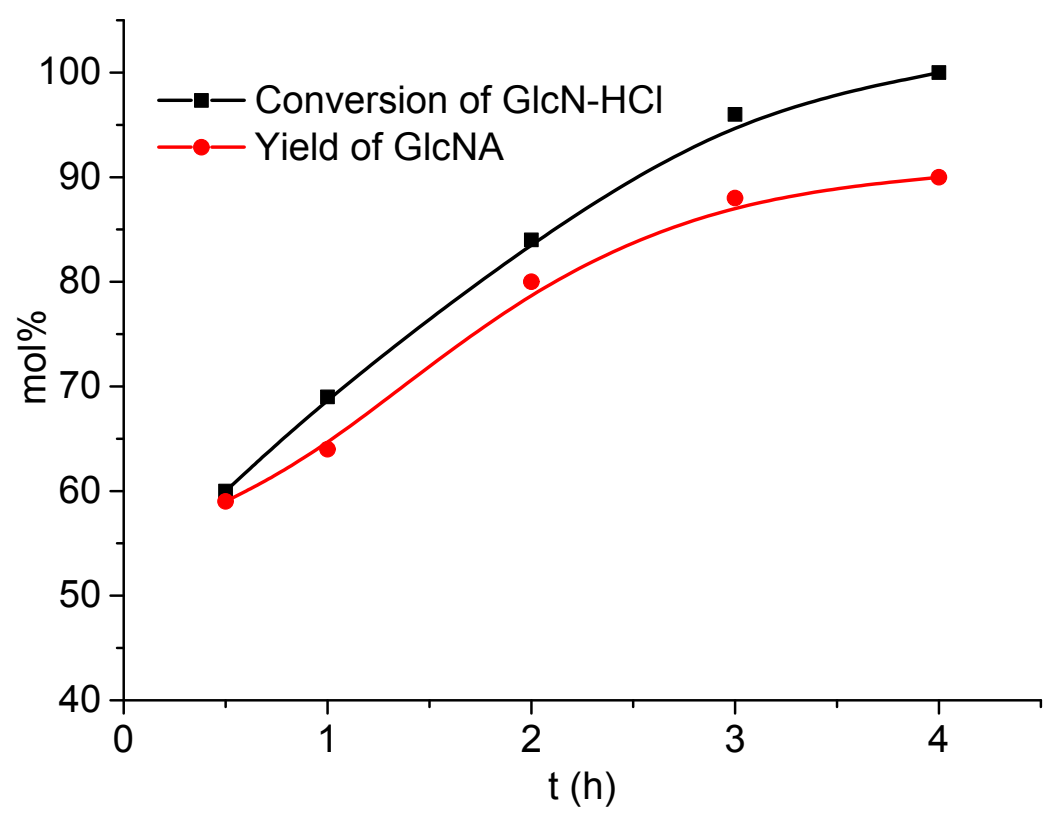

Figure S5. Effect of reaction time on the oxidation of GlcN-HCl.

Reaction conditions: $0.18 \mathrm{mmol}$ GlcN-HCl, $40 \mathrm{mg} \mathrm{Au} / \mathrm{MgO}-300,3 \mathrm{~mL}$ water, 5 bar $\mathrm{O}_{2}, 40{ }^{\circ} \mathrm{C}$. 

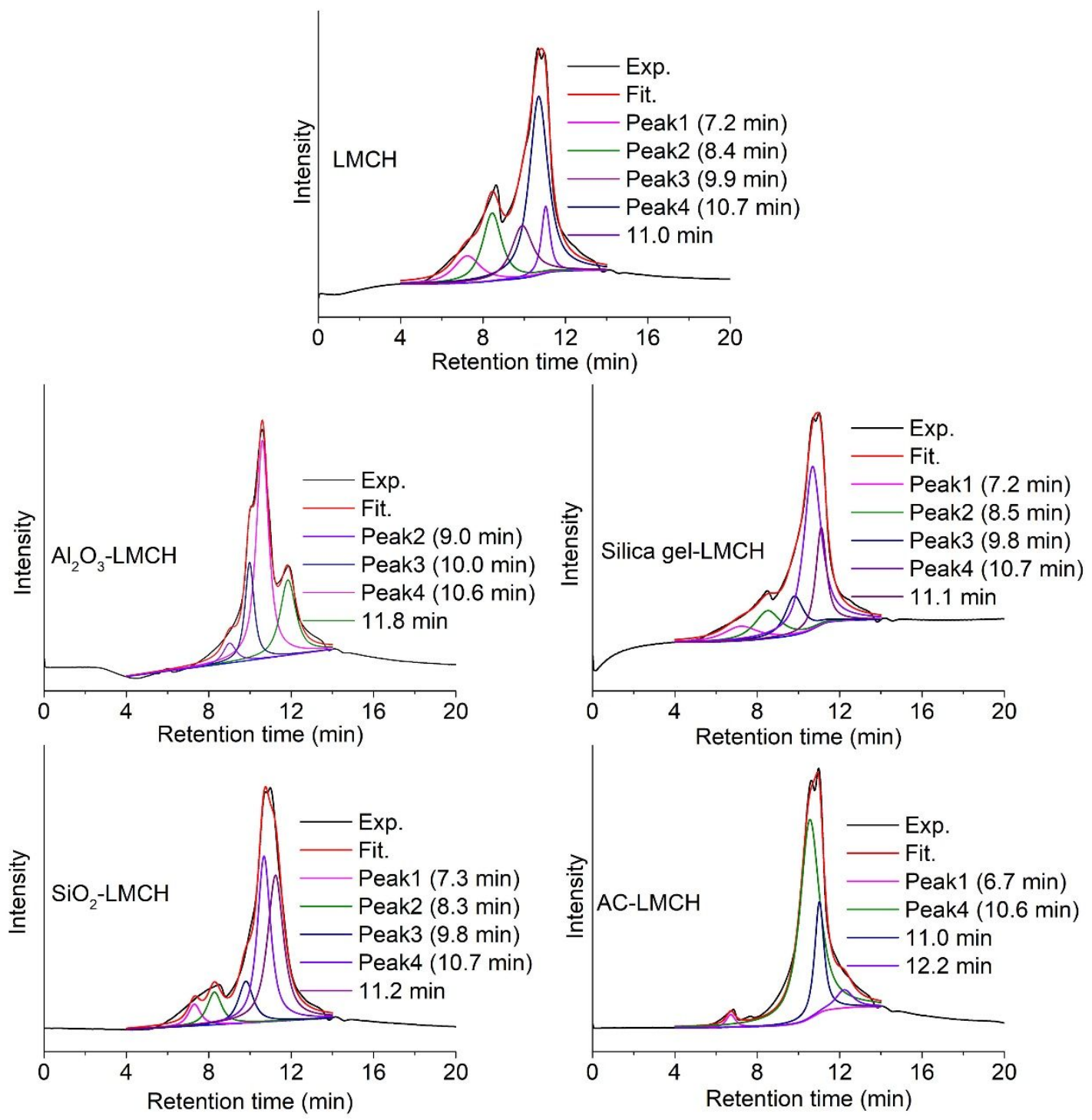

Figure S6. The deconvolution of GPC spectra of $\mathrm{LMCH}, \mathrm{Al}_{2} \mathrm{O}_{3}-\mathrm{LMCH}$, Silica gel-LMCH, $\mathrm{SiO}_{2}-\mathrm{LMCH}$, and AC-LMCH. 
Table S2. Retention time (min) and percentage of each component in GPC spectra. ${ }^{\text {a }}$

\begin{tabular}{|c|c|c|c|c|c|c|}
\hline Entry & Sample & Peak1 & Peak2 & Peak3 & Peak4 & $\begin{array}{l}\text { Peak } \\
(3 / 4)\end{array}$ \\
\hline 1 & $\mathrm{LMCH}$ & $7.2(11 \%)$ & $8.4(20 \%)$ & $9.9(17 \%)$ & $10.7(51 \%)$ & 0.34 \\
\hline 2 & $\begin{array}{l}\mathrm{Al}_{2} \mathrm{O}_{3}- \\
\mathrm{LMCH}\end{array}$ & - & $9.0(7 \%)$ & $10.0(23 \%)$ & $10.6(70 \%)$ & 0.34 \\
\hline 3 & $\begin{array}{c}\text { Silica gel- } \\
\mathrm{LMCH}\end{array}$ & $7.2(11 \%)$ & $8.5(15 \%)$ & $9.8(15 \%)$ & $10.7(59 \%)$ & 0.26 \\
\hline 4 & $\begin{array}{c}\mathrm{SiO}_{2^{-}} \\
\mathrm{LMCH}\end{array}$ & $7.3(7 \%)$ & $8.3(13 \%)$ & $9.8(18 \%)$ & $10.7(62 \%)$ & 0.28 \\
\hline 5 & $\begin{array}{c}\text { AC- } \\
\text { LMCH }\end{array}$ & $6.7(3 \%)$ & - & - & $10.6(97 \%)$ & 0 \\
\hline
\end{tabular}

a Spectra were presented in Fig. S5. Peaks with retention time longer than $11 \mathrm{~min}$ were not included.

Note: The retention time of GlcN was ca. 10.7 min (peak 4), longer than that of the polymeric by-products. The relative amount of peak 3 could be described by the area ratio of peak (3/4), because there is no substantial GlcN concentration changes after adsorptions. We found a negative correlation between Peak (3/4) and GlcNA yield. For $\mathrm{LMCH}$ and $\mathrm{Al}_{2} \mathrm{O}_{3}-\mathrm{LMCH}$, peak (3/4) was 0.34 and GlcNA yields were $17 \%$ and $19 \%$, respectively. With the decrease of peak (3/4) to 0.26 (Silica gel-LMCH) and $0.28\left(\mathrm{SiO}_{2}-\mathrm{LMCH}\right), 35 \%$ yield of GlcNA was obtained. The results indicated that peak 3 might be crucial for oxidation in second step. Although it is unclear at current stage what is the exact structure of compounds in peak 3, we postulate that it is a humin like polymers since humin binds to Au stronger than saccharides. 